\title{
Analisis Faktor Pendorong Perubahan Tutupan Lahan selama Satu Dekade di Kabupaten Labuhanbatu Utara
}

\author{
Regan Leonardus Kaswanto ${ }^{1,2}$, Ruth Mevianna Aurora², Doni Yusri²,3, Sofyan Sjaf2,4
}

${ }^{1}$ Divisi Manajemen Lanskap, Departemen Arsitektur Lanskap, Fakultas Pertanian, IPB University; e-mail: kaswanto@apps.ipb.ac.id

${ }^{2}$ Pusat Studi Pembangunan Pertanian dan Pedesaan - Lembaga Penelitian dan Pengabdian kepada Masyarakat (PSP3-LPPM), IPB University

${ }^{3}$ Program Studi Manajemen Industri, Sekolah Vokasi, IPB University

${ }^{4}$ Divisi Sosiologi Pedesaan dan Pengembangan Masyarakat, Departemen Sains Komunikasi dan Pembangunan, Fakultas Ekologi Manusia, IPB University

\begin{abstract}
ABSTRAK
Mengacu pada Undang Undang Republik Indonesia Nomor 23 Tahun 2008, sejak tanggal 24 Juni 2008 Kabupaten Labuhanbatu Utara (Labura) mulai berdiri sendiri sebagai kabupaten dan terpisah dari Kabupaten Labuhanbatu Selatan. Pada dasarnya wilayah pemekaran memiliki tujuan untuk meningkatkan kesejahteraan masyarakat. Berdasarkan data BPS tahun 2019, sektor unggulan dan mata pencaharian di Kabupaten Labura adalah pertanian. Akan tetapi seiring berjalannya waktu usaha pertanian semakin menurun. Hal ini terjadi diduga karena perubahan tutupan lahan. Secara geografis pemekaran wilayah akan mempengaruhi perubahan tutupan penggunaan lahan. Oleh karena itu untuk mengetahui seberapa besar perubahan yang terjadi perlu dilakukan analisis tutupan lahan tahun 2010-2019, kurang lebih 10 tahun setelah masa pemekaran terjadi. Analisis tutupan lahan satu dekade ini dilakukan menggunakan Citra Landsat yang diolah melalui metode klasifikasi penggunaan dan perubahan lahan. Hasilnya Kabupaten Labura mengalami perubahan yang relatif lambat. Perkebunan karet dan sawit mengalami perluasan lahan yang besar sedangkan hutan mangrove berubah fungsi dominan menjadi perkebunan. Sementara lahan terbuka mengalami perubahan terkecil yang juga mengarah ke perkebunan. Setelah dilakukan analisis tutupan lahan, dilakukan Seleksi Bivariat dengan menggunakan metode Logistic Regression Analysis (LRA) untuk mendapatkan faktor pendorong perubahan. Ada 7 variabel yang diduga mempengaruhi perubahan yaitu 1) jenis tanah, 2) kemiringan lereng, 3) curah hujan, 4) jumlah penduduk, 5) kepadatan penduduk, 6) jarak dari pusat kecamatan, dan 7) jarak dengan jalan utama. Hasil analisis menunjukan 6 variabel mempengaruhi dan hanya 1 variabel yakni curah hujan yang tidak mempengaruhi. Nilai positif pengaruh terbesar adalah jenis tanah. Semakin subur tanah maka perubahan semakin cepat terjadi. Nilai negatif pengaruh terbesar adalah jarak dari pusat kota yaitu kecamatan. Semakin jauh jarak dengan pusat kota, perubahan semakin cepat terjadi. Hal ini terjadi karena perkebunan dan pertanian yang lebih banyak mengalami perubahan berada jauh dari pusat pemukiman kecamatanan. Rekomendasi berupa perlunya zonasi tata ruang dan pengawasan alih fungsi lahan.
\end{abstract}

Kata kunci: Analisis spasial, Klasifikasi penggunaan lahan, Pemekaran wilayah, Peningkatan lahan perkebunan, Perubahan lahan

\begin{abstract}
Referring to the Law of the Republic of Indonesia Number 23 of 2008, since June 24, 2008 Labuhanbatu Utara (Labura) Regency began to stand alone as a self-government district and separated from Labuhanbatu Selatan Regency. The administrative direction which effects the expansion area has purpose for improving the social welfare essentially. Based on 2019 BPS data, the leading sector and livelihood in Labura Regency is agriculture. However, agricultural business is decreasing by year. This occurs due to changes in land cover. Geographically, the area will affect changes in land use cover. Therefore, to observe the major changes that have occurred, it is necessary to carry out an analysis of the land cover in 2010-2019, approximately 10 years after the expansion period until now. The analysis of a decade land cover analysis was carried out using Landsat Imagery processed through the classification method of land use and change. The result comes with no significant changes or changes are slow occur in period time. The plantation encompass palm oil and rubber has increased while mangrove has been decreased and changed into plantation area generally. Meanwhile the land built area has also decreased with the lowest percentage into the plantation area. Following the land use changes analysis, Bivariat Selection using Logistic Regresion Analysis (LRA) method is carried out to obtain the driving factor. There are 7 variables affect the land use changes namely 1) soil type, 2) slope, 3) rainfall, 4) total population, 5) population density, 6) distance from district center, and 7) distance to the main road. The analysis result shows 6 variables that influence and only 1 variable, namely rainfall that does not affect. The main of positive value is soil type. Soil fertility leads the changes of land use simultaneously. The more fertile, the changes of land will frequently occur. Furthermore, the main of negative value is distance to from the city center as the farther distance from district center, the changes of land will frequently occur. Recommendations are spatial zoning and land cover changing monitoring.
\end{abstract}


Kaswanto, R.L., Aurora, R.M., Yusri, D., dan Sjaf, S. (2021). Analisis Faktor Pendorong Perubahan Tutupan Lahan selama Satu Dekade di Kabupaten Labuhanbatu Utara. Jurnal IImu Lingkungan, 19(1), 107-116, doi:10.14710/jil.19.1.107-116

Keywords: Landuse changes, Landuse classification, Increasing plantation area, Region expansion, Spatial analysis

Citation: Kaswanto, R.L., Aurora, R.M., Yusri, D., dan Sjaf, S. (2021). Analisis Faktor Pendorong Perubahan Tutupan Lahan selama Satu Dekade di Kabupaten Labuhanbatu Utara. Jurnal Ilmu Lingkungan, 19(1), 107-116, doi:10.14710/jil.19.1.107-116

\section{Pendahuluan}

Berdasarkan Undang-Undang Nomor 32 Tahun 2004, Pasal 4 menyebutkan bahwa pembentukan daerah otonom dapat berupa pemekaran dari satu daerah menjadi dua daerah atau lebih (Republik Indonesia, 2004). Kabupaten Labuhanbatu Utara (Labura) merupakan salah satu daerah yang berada di kawasan Pantai Timur Sumatera Utara. Secara geografis, kabupaten ini berbatasan langsung dengan Selat Malaka di sebelah utara. Mengacu pada Undang Undang Republik Indonesia No 23 Tahun 2008, sejak tanggal 24 Juni 2008, Kabupaten Labura mulai berdiri sendiri sebagai kabupaten dan terpisah dari Kabupaten Labuhanbatu Selatan (Republik Indonesia, 2008). Sehingga menjadi sangat menarik melihat perubahan tutupan lahan selama satu dekade (10 tahun) yang terjadi setelah pemekaran dilaksanakan.

Berkaitan dengan kebijakan pemekaran wilayah, secara geografis pemekaran wilayah akan mempengaruhi perubahan tutupan penggunaan lahan. Hal ini didukung dalam Bourne (1982), yang menyatakan bahwa terdapat proses utama yang menyebabkan terjadinya perubahan guna lahan yaitu: (1) perluasan batas kota, (2) peremajaan di pusat kota, (3) perluasan jaringan infrastruktur, dan (4) tumbuh dan hilangnya pemusatan aktivitas tertentu. Sebagai wilayah yang berdiri sendiri, pusat Kabupaten Labura berada di Kecamatan Kualuh Hulu sehingga banyak pembangunan dan perkembangan yang dilakukan di wilayah ini yang mengarah pada perubahan tutupan penggunaan lahan.

Sebelum terjadi pemekaran, Kabupaten Labuhanbatu Utara dan Selatan merupakan satu wilayah otonomi daerah. Akan tetapi dengan adanya pemekaran, otonomi daerah memiliki taggung jawab untuk masing masing wilayah dalam meningkatkan kesejahteraan masyarakat. Pada dasarnya tujuan dari pemekaran daerah adalah mendekatkan pelayanan umum dari pemerintahan kepada masyarakat, dan meningkatkan kesejahteraan masyarakat setempat (Sunarno, 2006).

Data BPS dari tahun 2008-2019 menunjukkan bahwa lapangan pekerjaan masyarakat yang dominan di Kabupaten Labura adalah pertanian. Di samping itu potensi atau sektor unggulan di Kabupaten Labura adalah sektor pertanian. Akan tetapi data juga menunjukan bahwa usaha pertanian menurun seiring waktu. Perkembangan wilayah terbangun mempengaruhi perubahan tutupan lahan. Tingkat perkembangan wilayah dapat dilihat dari rasio luas wilayah terbangun (built-up area) terhadap total luas wilayah. Semakin besar wilayah terbangun, maka semakin tinggi tingkat perkembangan wilayahnya (Kurniati et al., 2012).

Konversi lahan dipengaruhi oleh faktor eksternal, internal dan kebijakan pemerintah. Menurut Kustiawan (1997), faktor eksternal meliputi faktor 108 dinamika pertumbuhan perkotaan, baik secara spasial, demografis maupun ekonomi yang memacu atau mendorong terjadinya konversi lahan pertanian. Faktor internal adalah kondisi sosial ekonomi rumah tangga pertanian penggunaan lahan yang mendorong mereka melepaskan pemilikan atau penggunaan lahannya. Faktor internal menyangkut pertumbuhan rumah tangga pertanian dan pengguna lahan.

Berdasarkan hal di atas maka sangat diperlukan penelitian untuk melakukan analisis mengenai perubahan tutupan penggunaan lahan di Kabupaten Labura dalam kurun waktu kurang lebih satu dekade (10 tahun) setelah pemekaran yaitu pada tahun 2010 dan 2019. Kemudian diperlukan analisis faktor pendorong perubahan sehingga diketahui arah penyebab terjadinya perubahan tersebut. Dengan demikian, tujuan dari penelitian ini adalah 1) menganalisis perubahan tutupan lahan selama satu dekade, 2) menentukan faktor pendorong perubahan tutupan lahan, dan 3) memberikan rekomendasi manajemen tata ruang Kabupaten Labura.

\section{Metode Penelitian}

\subsection{Lokasi dan Waktu Penelitian}

Penelitian ini dilaksanakan di Kabupaten Labura yang terdiri dari 8 (delapan) kecamatan yaitu Aek Kuo, Aek Natas, Kualuh Hilir, Kualuh Hulu, Kualuh Leidong, Kualuh Selatan, Merbau, dan Na IX-X. Waktu penelitian ini dilaksanakan pada periode 2019-2020. Peta lokasi penelitian diperlihatkan pada Gambar 1.

\subsection{Alat dan Bahan}

Alat dan bahan yang digunakan adalah alat tulis menulis, kamera, Global Positioning System (GPS), perangkat lunak (software) Esri ArcGIS 10.5, dan Citra Landsat untuk analisis tutupan lahan di Kabupaten Labura.

\subsection{Jenis dan Teknik Pengumpulan Data}

Data yang digunakan pada penelitian ini terdiri data Peta Tutupan Lahan dan Peta Topografi yang diambil dari Citra Landsat tahun 2019 (Landsat 8 Oli/Tris yang diakuisisi pada tanggal 19 Juli 2019) dan tahun 2010 (Landsat 7 ETM+ yang diakuisisi pada tanggal 10 Mei 2010), Peta Tutupan Lahan yang dianalisis menggunakan Digital Elevation Model (DEM) untuk memperoleh informasi mengenai ketinggian dan kemiringan (Zhou, 2017), Peta Jenis Tanah yang bersumber dari BBSLDP Kota Bogor 2017, Peta Curah Hujan, Kepadatan Penduduk, Jumlah Penduduk, Peta Geografis, dan Peta Rencana Tata Ruang Wilayah (RTRW) tahun 2019 yang diperoleh dari Dinas Kabupaten Labura.

Sementara itu terdapat Peta Jarak dari Pusat Kecamatan. Peta ini dihasilkan dengan menggunakan fungsi euclidean distance (Greenacre and Primicerio, 2013) pada ArcGIS, yaitu membuat area buffer dari 
titik-titik pusat kecamatan. Terdapat tujuh titik pusat kecamatan di Kabupaten Labura yaitu Kecamatan Kualuh Hulu, Kualuh Selatan, Kualuh Leidong, Kualuh Hilir, Merbau, Na IX-X dan Aek Kuo. Kemudian dibutuhkan juga Peta Jarak dari Jalan Utama yang dibuat dengan fungsi yang sama dengan jarak dari pusat kecamatan, yaitu fungsi euclidean distance.

Selain itu dilakukan ground truth check (GTC) pada lanskap untuk mengambil data primer berupa dokumentasi saat sruvei lapang (Rujoiu-Mare and Mihai, 2016). Kemudian wawancara dengan tiga narasumber terkait kondisi tapak sepuluh tahun yang lalu. Tiga narasumber ini mewakili kalangan pemerintah, akademisi dan masyarakat. Selanjutnya dilakukan pengamatan untuk melihat kondisi aktual yang ada di Kabuaten Labura (Pickles, 1995).

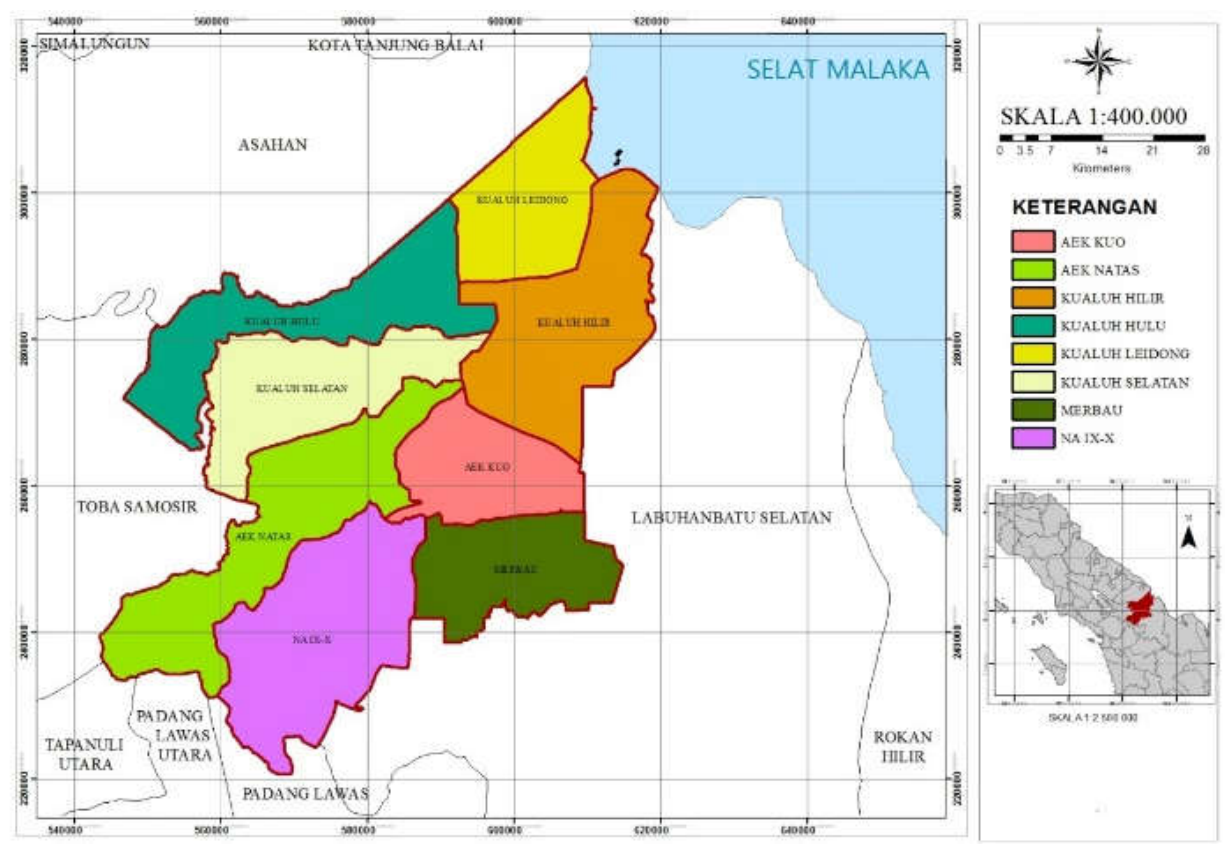

Gambar 1. Peta Geografi Kabupaten Labura Provinsi Sumatera Utara

\subsection{Analisis Data}

\subsubsection{Analisis Perubahan Tutupan Lahan}

Secara spasial, perubahan penutupan lahan tidak dapat terlihat dalam kurun waktu yang relatif singkat, sehingga fakta yang ingin diketahui dari perubahan tersebut tidak dapat digali secara optimal karena kurangnya sumber data, sehingga metode penelitian ini menggabungkan data obervasi dan wawancara. Perubahan penutupan lahan yang dianalisis pada penelitian ini dibatasi pada tahun 2010 sampai 2019. Hal ini dilakukan berdasarkan pengamatan konversi tutupan lahan setelah 2 tahun masa pemekaran sejak 2008 dan kondisi saat ini.

Analisis penutupan dan pengggunaan lahan diklasifikasikan menjadi 7 (tujuh) yaitu badan air, hutan, perkebunan, lahan kosong, pemukiman, pertanian sawah, dan semak belukar. Klasifikasi tutupan lahan mengacu pada SNI 7645 (Standar Nasional Indonesia, 2010). Pada citra tahun 2010 terdapat garis-garis hitam (stripping line) yang menutupi sebagian besar citra tersebut, sehingga informasi pixel number yang ingin didapatkan dari citra tersebut tidak optimal sehingga perlu dilakukan Radiometric Correction atau Fixing Landsat 7 Scanline Error terlebih dahulu. Kondisi citra Landsat yang berawan di beberapa piksel pada scene lokasi penelitian mengharuskan dilakukannya pengklasifikasian dua kelas penutupan lahan tambahan, yaitu awan dan bayangan awan. Awan dan bayangannya didefinisikan sebagai kelas yang tidak memiliki informasi pixel number apapun mengenai tutupan lahan atau biasa disebut data kosong.

Hasil klasifikasi peta penutupan lahan tahun 2010 diuji tingkat akurasinya dengan menggunakan metode accuraccy assessment. Uji akurasi tersebut disajikan dalam bentuk matriks kesalahan yang didapatkan setelah membandingkan tutupan lahan hasil deliniasi dengan reference point untuk tutupan lahan sebenarnya dengan menggunakan software ArcGIS 10.5. Metode yang digunakan untuk menghitung akurasi klasifikasi tutupan lahan dengan menggunakan matriks kesalahan atau confusion matrix/error matrix. Selanjutnya dilakukan perhitungan producer's accuracy, user's accuracy, overall accuracy dan nilai Indeks Kappa (Jensen, 2005; Wulansari, 2018).

Akurasi Pembuat (producer's accuracy) merupakan akurasi yang dilihat dari sisi pembuat peta dengan akurasi yang diperoleh melalui pembagian jumlah total piksel dari data acuan per kelas klasifikasi (Stehman, 1997). Pada tabel pendugaan akurasi di atas diketahui bahwa akurasi pembuat tertinggi adalah kelas awan, hutan, lahan kosong, hutan mangrove, lahan terbangun dan semak yaitu sebesar 100\%, sedangkan untuk Akurasi Pembuat terendah terdapat pada bayangan awan, yaitu sebesar $50 \%$. Selain akurasi pembuat juga terdapat Akurasi Pengguna (user's accuracy). Akurasi Pengguna 
merupakan akurasi yang dilihat dari sisi pengguna petanya yang diperoleh melalui pembagian antara jumlah piksel yang benar dengan total keseluruhan piksel setiap kelas klasifikasi, akurasi ini disebut dengan istilah kesalahan komisi (Commission Error) (Wiggers et al., 2020).

Deteksi perubahan penutupan lahan dilakukan dengan mengubah data raster ke poligon terlebih dahulu dengan ArcGis 10.5 untuk memudahkan perhitungan, kemudian dilakukan overlay pada kedua peta dengan menggunakan tool intersect. Peta perubahan lahan dibuat menggunakan metode IF pada atribut tabel hasil overlay kedua peta. Jika atribut kode menunjukan perbedaan, maka terjadi perubahan pada tutupan lahan. Namun, jika atribut kode tidak menunjukan perbedaan maka diasumsikan tidak terjadi perubahan pada tutupan lahan di Kabupaten Labura. Perhitungan perubahan tiap tutupan lahan dilakukan dengan menggunakan pivot table pada Microsoft Excel sehingga output yang didapat langsung berupa matriks perubahan tutupan lahan dari tahun 2010 hingga 2019.

\subsubsection{Analisis Faktor Pendorong Perubahan Tutupan Lahan}

Penutupan dan penggunaan lahan serta perubahannya (Y) telah diidentifikasi penyebabnya. Diduga terdapat tujuh variabel yang mempengaruhi perubahan penutupan lahan di Kabupaten Labura, yaitu jenis tanah (X1), kemiringan lereng (X2), curah hujan (X3), jumlah penduduk (X4), kepadatan penduduk (X5), jarak dari pusat kecamatan (X6), dan jarak dengan jalan utama (X7).

Setelah dilakukan Seleksi Bivariat dengan menggunakan metode Logistic Regression Analysis (LRA) muncul persamaan regresi. Nilai positif pada variabel mengartikan bahwa semakin tinggi nilai variabel tersebut, maka perubahan lahan semakin sering terjadi, sebaliknya nilai negatif mengartikan bahwa semakin tinggi nilai variabel, maka perubahan lahan pada piksel tersebut semakin jarang atau tidak terjadi.

\section{Hasil dan Pembahasan \\ 3.1. Kondisi Penelitian}

Secara geografis Kabupaten Labura diapit oleh kabupaten lainnya yaitu Kabupaten Asahan dan Selat Malaka di bagian Utara, Kabupaten Labuhanbatu Selatan di bagian Timur, Kabupaten Tapanuli Selatan dan Padang Lawas Utara di bagian Selatan, dan Kabupaten Toba Samosi dan Kabupaten Tapanuli Utara di bagian Utara. Sebagian besar tanah di Kabupaten Labura berasal dari jenis hapludults, endoaquepts, dystrudepts, dan haplosaprists dengan satuan tanah pada grup tektonik, vulkanik, alluvial, marin, dan fluvio-marin. Hal ini mengindikasikan bahwa Kabupaten Labura memiliki kesuburan yang tinggi. Dapat diketahui bahwa wilayah Kabupaten Labura memiliki wilayah dominan dengan karakteristik datar dan berbukit kecil agak curam di daerah hutan di Kecamatan Aek Natas dan Na IX-X.
Berdasarkan data BPS tahun 2017, curah hujan rata-rata Kabupaten Labura pada periode 5 tahun yang dimulai dari tahun 2013-2017 memiliki curah hujan sekitar 2.000-3.500 $\mathrm{mm} /$ tahun. Hal ini menunjukan bahwa curah hujan normal bagi wilayah tropis Indonesa. Selain itu berdasarkan hasil perhitungan dari data BPS tahun 2017, Kecamatan Kualuh Hulu merupakan kecamatan dengan jumlah penduduk terbanyak dan Kecamatan Kualuh hilir sebagai kecamatan terendah. Kepadatan penduduk tertinggi di Kecamatan Kualuh Hulu, Kualuh Selatan, dan Merbau.

\subsection{Analisis Perubahan Tutupan dan Penggunaan Lahan}

Jenis penutupan dan penggunaan lahan yang diamati pada penelitian ini sesuai dengan kelas penutupan dan penggunaan lahan yang telah ditentukan sebelumnya, yakni 7 kelas berupa badan air, hutan, perkebunan, lahan kosong, pemukiman, pertanian sawah, dan semak belukar. Hasil klasifikasi dari masing-masing kelas memiliki kendala tersendiri yang dijelaskan di bawah ini.

\subsubsection{Badan Air}

Jenis badan air yang diklasifikasikan menjadi kelas penutupan lahan badan air adalah sungai. Sungai yang mengalir pada Kabupaten Labura berhilir langsung ke Selat Malaka. Klasifikasi badan air menggunakan Citra Landsat yang memiliki resolusi menengah namun cenderung sulit dan kurang akurat karena ukurannya yang realtif kecil serta warna yang tampak mirip dengan tutupan lahan lain sehingga seringkali tidak terklasifikasi secara spasial.

\subsubsection{Hutan}

Hutan adalah suatu kesatuan ekosistem berupa hamparan lahan berisi sumber daya hayati yang didominasi pepohonan dalam persekutuan alam lingkungannya, yang satu dengan lainnya tidak dapat dipisahkan. Hutan di Kabupaten Labura meliputi hutan yang dekat dengan pegunungan dan hutan mangrove yang berada di sekitar pantai di Kecamatan Hilir dan Kecamatan Leidong. Klasifikasi hutan pada citra memiliki tutupan yang sama dengan perkebunan sehingga agak sulit teridentifikasi khususnya hutan mangrove.

\subsubsection{Perkebunan}

Perkebunan adalah kegiatan yang mengusahakan tanaman pada media tumbuh dalam ekosistem yang sesuai. Tanaman yang ditanam umumnya berukuran besar dan waktu penanaman relatif lama. Perkebunan di Kabupaten Labura didominasi oleh perkebunan sawit, karet, dan kelapa. Luas lahan perkebunan mendominasi hampir seluruh luasan kabupaten. Klasifikasi perkebunan memiliki tutupan yang hampir sama dengan hutan namun pada perkebunan tanaman ditanam secara monokultur dengan sistem jarak yang teratur dalam bidang-bidang yang cenderung geometris sehingga dapat dengan mudah dibedakan dari pantauan Citra Landsat. 


\subsubsection{Lahan Terbuka}

Lahan terbuka merupakan lahan tanpa tutupan baik yang bersifat alami, semi alami maupun artifisial. Lahan terbuka yang teridentifikasi meliputi lahan perkebunan sebelum replanting dan lahan kosong sebelum pembangunan. Klasifikasi lahan terbuka di
Kabupaten Labura memiliki warna yang menyerupai badan air sehingga sulit terklasifikasi secara spasial, namun masih dapat dibedakan secara associative judgement, yakni dengan kedekatannya terhadap permukiman dan perkebunan.

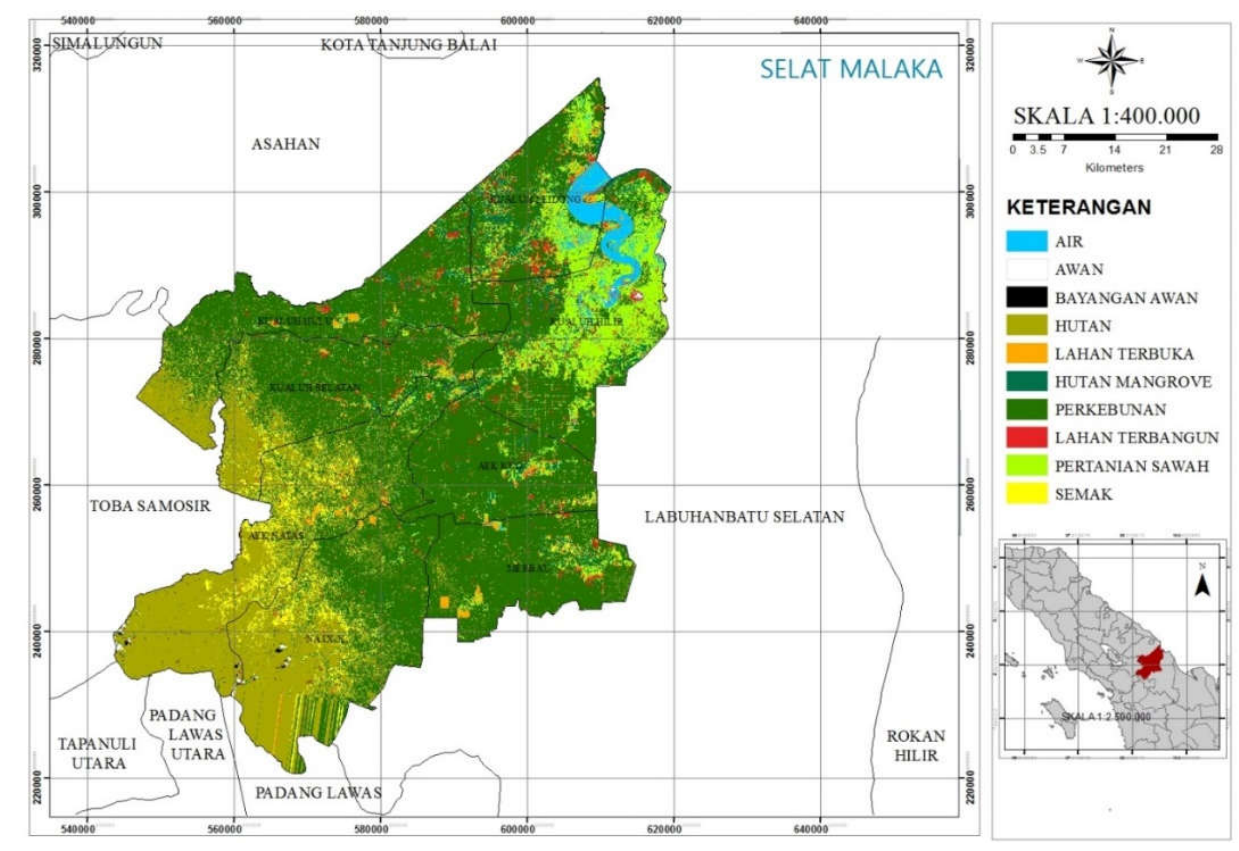

Gambar 2. Tutupan Lahan Kabupaten Labura pada Tahun 2010

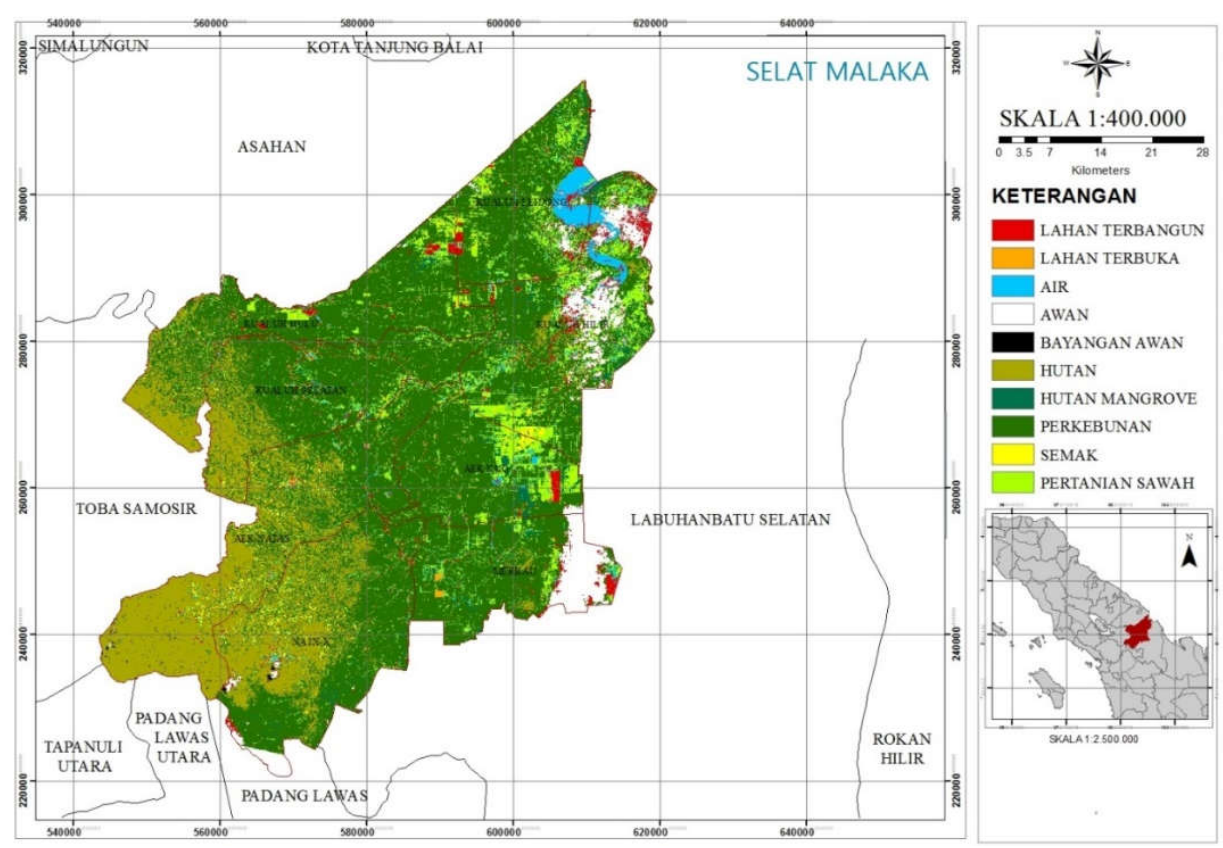

Gambar 3. Tutupan Lahan Kabupaten Labura pada tahun 2019

\subsubsection{Lahan Terbangun}

Lahan terbangun merupakan penutupan lahan yang terdiri dari lahan-lahan terbangun, baik perumahan, kawasan industri, maupun lahan perkotaan. Lahan terbangun di Kabupaten Labura meliputi pemukiman, pabrik, kantor, dan area industri Karakteristik lahan tidak serapat seperti di kota-kota besar. Berdasarkan hasil pengamatan, karakter lahan terbangun Kabupaten Labura terlihat dari jarak antar pemukiman dengan pemukiman lain yang jarang dan pembangunannya cenderung mengikuti jalur jalan (street development). Perkembanga jenis ini senantiasa diikuti oleh faktor budaya yang melihat akses sebagai hal utama dan memudahkan (Kim, 2017).

\subsubsection{Pertanian Sawah}

Sawah merupakan tanah yang digarap dan diairi untuk menanam padi. Sawah pada Kabupaten Labura merupakan sawah tadah hujan yaitu sawah yang 
pengairannya berasal dan mengandalkan air hujan. Luas lahan pertanian di kabupaten ini tidak sebesar lahan perkebunan. Klasifikasi lahan pertanian pada citra memiliki tutupan dengan bidang-bidang berukuran lebih kecil dengan warna yang lebih terang dari perkebunan. Akibat musim penghujan, tutupan lahan pertanian banyak tergenang oleh air.

\subsubsection{Semak Belukar}

Semak merupakan lahan kering yang ditumbuhi berbagai vegetasi alamiah kerap homogen dengan tingkat kerapatan jarang hingga rapat didominasi vegetasi rendah bertipe alamiah. Semak pada Kabupaten Labura menyebar pada setiap kecamatan dengan luas lahan yang kecil dan berada dekat dengan perkebunan. Tanaman yang tumbuh pada lahan semak adalah teki (Cyperus rotundus), alang-alang (Imperata cylindrical Reusch), dan jenis paku-pakuan. Klasifikasi semak dalam Citra Landsat memiliki warna terang.

Kebutuhan manusia akan lahan yang sangat tinggi mendorong terjadinya konversi lahan. Jenis penutupan dan penggunaan lahan yang diamati pada penelitian ini sesuai dengan kelas penutupan dan penggunaan lahan SNI, yaitu badan air, hutan, perkebunan, lahan kosong, pemukiman, pertanian, dan semak belukar.

\subsubsection{Perubahan Tutupan lahan Tahun 2010- 2019}

Secara spasial, perubahan tutupan lahan di Kabupaten Labura dominan tetap (tidak berubah) dari total luas kawasan, yakni $82,21 \%$ sementara luas kawasan yang mengalami perubahan adalah $17,79 \%$ (Gambar 4). Hal ini berarti ada perubahan tutupan lahan dengan laju 1,8\% per tahun. Luas badan air dan perkebunan mengalami pertambahan yang ditandai oleh tanda positif (+). Sedangkan luas lahan terbangun, hutan, hutan mangrove, pertanian sawah, dan semak mengalami penurunan yang ditandai oleh tanda negatif (-). Tabel 1 menunjukan bahwa perubahan luas lahan tertinggi terjadi pada perkebunan yaitu sebesar $4,16 \%$ dan pertanian sawah sebagai perubahan luas terendah sebesar $0,08 \%$.

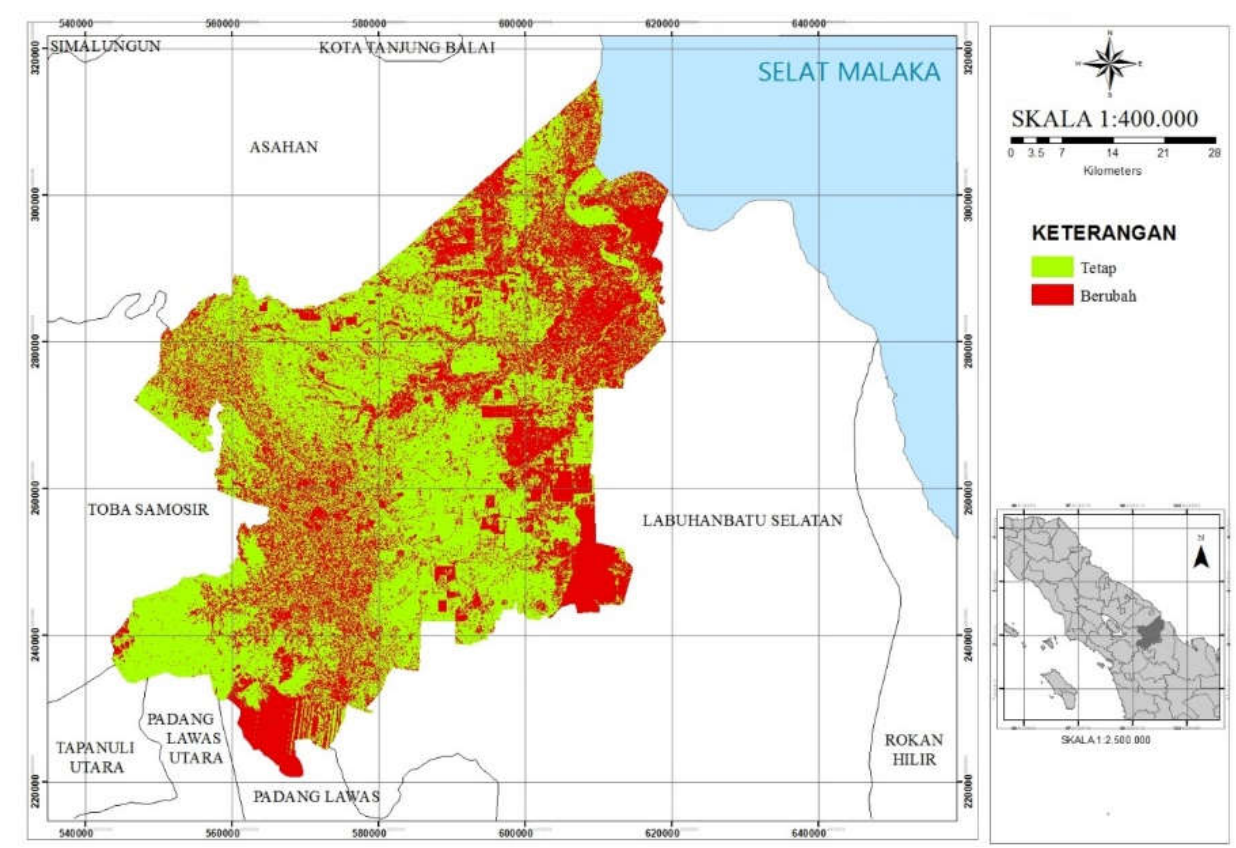

Gambar 3. Perubahan Tutupan Lahan tahun 2010-2019

Tabel 1. Perubahan Luas Tutupan Lahan Kabupaten Labura 2010-2019

\begin{tabular}{|c|c|c|c|c|c|c|c|}
\hline \multirow{2}{*}{ No } & \multirow{2}{*}{ Tutupan Lahan } & \multicolumn{2}{|c|}{ Tahun 2010} & \multicolumn{2}{|c|}{ Tahun 2019} & \multicolumn{2}{|c|}{ Perubahan } \\
\hline & & Luas (ha) & Luas (\%) & Luas (ha) & Luas (\%) & Luas (ha) & Luas (\%) \\
\hline 1 & Lahan Terbangun & $11.031,33$ & 2,98 & $1.0064,30$ & 2,72 & $-967,02$ & $-0,26$ \\
\hline 2 & Badan Air & $8.407,44$ & 2,27 & $9.830,14$ & 2,66 & $+1.422,71$ & $+0,38$ \\
\hline 3 & Hutan & $70.280,02$ & 19,01 & $66.894,63$ & 18,10 & $-3.385,39$ & $-0,92$ \\
\hline 4 & Hutan Mangrove & $16.636,51$ & 4,50 & $7.730,76$ & 2,09 & $-8.905,75$ & $-2,41$ \\
\hline 5 & Perkebunan & $203.305,70$ & 55 & $218.694,59$ & 59,16 & $+15.388,94$ & $+4,16$ \\
\hline 6 & Pertanian Sawah & $34.219,42$ & 9,26 & $33.918,16$ & 9,18 & $-301,26$ & $-0,08$ \\
\hline 7 & Semak & $19.176,96$ & 5,19 & $5.664,03$ & 1,53 & $-13.512,93$ & $-3,66$ \\
\hline 8 & Lahan Terbuka & $5.753,37$ & 1,56 & 633,19 & 0,17 & $-5.120,18$ & $-1,39$ \\
\hline 9 & Awan (Data Kosong) & $6.01,26$ & 0,16 & 15912,80 & 4,30 & $+15.311,54$ & $+4,14$ \\
\hline 10 & Bayangan Awan (Data Kosong) & 235.6 & 0,06 & 304,94 & 4,30 & $+1.422,71$ & $+0,39$ \\
\hline & Total & & 100,00 & & 100,00 & & \\
\hline
\end{tabular}


Tabel 2. Matriks Perubahan Penutupan Lahan di Kabupaten Labura 2010-2019

\begin{tabular}{|c|c|c|c|c|c|}
\hline \multicolumn{3}{|c|}{ Air } & \multicolumn{3}{|c|}{ Hutan } \\
\hline Perubahan & Luas (ha) & Luas (\%) & Perubahan & Luas (ha) & Luas (\%) \\
\hline Air Tetap & $4.236,31$ & 43,10 & Hutan tetap & $48.377,16$ & 72,32 \\
\hline Air ke hutan & 228,43 & 2,32 & Hutan ke air & 20,97 & 0,03 \\
\hline Air ke lahan kosong & 408,64 & 4,16 & Hutan ke lahan kosong & 224,76 & 0,34 \\
\hline Air ke mangrove & 343,85 & 3,50 & Hutan ke mangrove & 128,98 & 0,19 \\
\hline Air ke perkebunan & $2.199,44$ & 22,37 & Hutan ke perkebunan & $13.090,31$ & 19,57 \\
\hline Air ke lahan terbangun & 559,35 & 5,69 & Hutan ke lahan terbangun & 413,83 & 0,62 \\
\hline Air ke sawah & $1.672,12$ & 17,01 & Hutan ke sawah & 580,58 & 0,87 \\
\hline Air ke semak & 149,70 & 1,52 & Hutan ke semak & $3.629,29$ & 5,43 \\
\hline \multicolumn{3}{|c|}{ Perkebunan } & \multicolumn{3}{|c|}{ Lahan Kosong } \\
\hline Perubahan & Luas (ha) & Luas (\%) & Perubahan & Luas (ha) & Luas (\%) \\
\hline Perkebunan tetap & $153.433,65$ & 70,16 & Lahan Kosong tetap & 44,49 & 7,03 \\
\hline Perkebunan ke hutan & $17.215,32$ & 7,87 & Lahan kosong ke hutan & 87,53 & 13,82 \\
\hline Perkebunan ke lahan kosong & $3.475,81$ & 1,59 & Lahan kosong ke Perkebunan & 7,24 & 1,14 \\
\hline Perkebunan ke mangrove & $10.631,48$ & 4,86 & Lahan kosong ke mangrove & 25,78 & 4,07 \\
\hline Perkebunan ke air & 957,91 & 0,44 & Lahan kosong ke air & 356,80 & 56,35 \\
\hline Perkebunan ke lahan terbangun & $6.212,76$ & 2,84 & Lahan kosong ke lahan terbangun & 29,17 & 4,61 \\
\hline Perkebunan ke sawah & $15.499,93$ & 7,09 & Lahan kosong ke sawah & 34,53 & 5,45 \\
\hline Perkebunan ke semak & $11.158,19$ & 5,10 & Lahan kosong ke semak & 45,00 & 7,11 \\
\hline \multicolumn{3}{|c|}{ Hutan Mangrove } & \multicolumn{3}{|c|}{ Lahan Terbangun } \\
\hline Perubahan & Luas (ha) & Luas (\%) & Perubahan & Luas (ha) & Luas (\%) \\
\hline Mangrove Tetap & $1.185,74$ & 15,34 & Terbangun tetap & $1.261,30$ & 12,53 \\
\hline Mangrove ke hutan & 281,14 & 3,64 & Terbangunke hutan & 653,53 & 6,49 \\
\hline Mangrove ke lahan kosong & 96,66 & 1,25 & Terbangun ke lahan kosong & 422,71 & 4,20 \\
\hline Mangrove ke Air & 52,93 & 0,68 & Terbangunke mangrove & 454,69 & 4,52 \\
\hline Mangrove ke perkebunan & $4.358,69$ & 56,38 & Terbangun ke perkebunan & $4.020,20$ & 39,95 \\
\hline Mangrove ke lahan terbangun & 242,71 & 3,14 & Terbangun ke Air & 961,41 & 9,55 \\
\hline Mangrove ke sawah & $1.269,76$ & 16,42 & Terbangun ke sawah & $2.000,18$ & 19,87 \\
\hline Mangrove ke semak & 237,64 & 3,07 & Terbangun ke semak & 241,25 & 2,40 \\
\hline \multicolumn{3}{|c|}{ Sawah } & \multicolumn{3}{|c|}{ Semak } \\
\hline Perubahan & Luas (ha) & Luas (\%) & Perubahan & Luas (ha) & Luas (\%) \\
\hline Sawah tetap & $8.464,78$ & 24,96 & Semak ke semak & $2.149,89$ & 37,96 \\
\hline Sawah ke hutan & 46,32 & 0,14 & Semak ke hutan & 2,48 & 0,04 \\
\hline Sawah ke lahan kosong & 675,14 & 1,99 & Semak ke lahan kosong & 80,50 & 1,42 \\
\hline Sawah ke mangrove & $2.689,42$ & 7,93 & Semak ke mangrove & 228,11 & 4,03 \\
\hline Sawah ke perkebunan & $17.854,15$ & 52,64 & Semak ke perkebunan & $1.750,84$ & 30,91 \\
\hline Sawah ke lahan terbangun & $1.500,76$ & 4,42 & Semak ke lahan terbangun & 110,21 & 1,95 \\
\hline Sawah ke Air & 843,83 & 2,49 & Semak ke sawah & 218,31 & 3,85 \\
\hline Sawah ke semak & $1.089,11$ & 3,21 & Semak ke air & 15,39 & 0,27 \\
\hline
\end{tabular}

Berdasarkan Tabel 2, badan air mengalami pertambahan luas tutupan lahan pada tahun 2019. Secara spasial, badan air teridentifikasi berwarna coklat sehingga mempengaruhi klasifikasi lahan dalam pertambahan luas lahan. Luas yang bertambah ini dipengaruhi oleh lahan yang tergenang air seperti lahan kosong, perkebunan dalam masa replanting yang tergenang hujan, sawah saat padi dalam masa pembibitan atau sawah yang tergenang banjir. Berdasarkan hasil analisis perubahan luas air dominan ke arah perkebunan dan sawah pertanian lahan basah.

Selain itu perkebunan mengalami pertambahan luas lahan terbesar. Masyarakat Kabupaten Labura sangat mengandalkan perkebunan sebagai mata pencaharian utama. Hal ini dibuktikan dari luas lahan perkebunan mendominasi wilayah dan mengalami peningkatan dari tahun 2010-2019.

Akan tetapi perkebunan juga mengalami penurunan luas area yang dominan ke arah penutupan hutan. Secara spasial, tutupan lahan hutan dan perkebunan memiliki karakteristik warna yang mirip sehingga mempengaruhi klasifikasi keduanya. Selain itu hal ini juga mempengaruhi luas lahan sawah. Berdasarkan hasil analisis, sawah dan hutan mengalami perubahan lahan terbesar ke arah perkebunan. Lahan perkebunan saat tanaman usia muda berwarna hijau muda begitupula dengan lahan sawah yang juga berwarna hijau muda. Lahan sawah yang terdapat di Kecamatan Kualuh Leidong dan Kualih Hilir memiliki pola lahan yang berdekatan dan tumbuh berdampingan dengan perkebunan baik kelapa atau sawit sehingga saat sawit atau kelapa berada dalam masa pembibitan, lahan perkebunan akan terklasifikasi seperti sawah secara spasial berdasarkan warna.

Pada tahun 2019, semak juga mengalami perubahan lahan terbesar ke arah perkebunan. Selain itu hutan mangrove juga mengalami konversi lahan yang dominan ke arah perkebunan dan sawah. Hutan Mangrove tumbuh dekat dengan sungai yang mengarah langsung ke Selat Malaka. Perubahan ini diasumsikan karena kebutuhan pembukaan lahan oleh masyarakat. Berdasarkan peta RTRW, hutan mangrove adalah kawasan konservasi yang seharusnya dilestarikan. Akan tetapi seiring berjalannya waktu kebutuhan akan lahan membuat kawasan pesisir semakin berubah dan tidak lagi dijaga oleh masyarakat.

Perubahan juga diikuti oleh lahan terbuka, lahan ini mengalami penurunan luas lahan yang dominan ke penutupan badan air dan hutan. Perubahan ini diasumsikan karena adanya genangan air di permukaan lahan serta tumbuhnya tanaman alami 
hutan pada lahan kosong. Sementara itu hutan dan lahan terbangun juga mengalami penurunan luas lahan yang dominan ke arah perkebunan karet dan sawit. Kemudian, lahan sawah pada tahun 2019 mengalami perubahan yang dominan kearah perkebunan juga. Sawah mengalami perubahan lebih dari 50,0\% wilayah ke arah perkebunan di mana hutan hanya mengalami perubahan sekitar 19,57\%. Akibat nilai lahan yang rendah, penggunaan lahan untuk lanskap pertanian akan selalu dikalahkan oleh peruntukan perkebunan yang lebih menguntungkan. Sama seperti tutupan lahan lainnya, permasalahan perkebunan dikarenakan alasan finansial (Fauzi et al., 2016; Herman, Fahmuddin Agus, 2009; Kurniawan and Pangestu, 2018) .

\subsection{Analisis Faktor Pendorong Perubahan Penutupan Lahan}

Penutupan dan penggunaan lahan serta perubahannya telah diidentifikasi dan diduga penyebabnya. Diduga ada tujuh variabel yang mempengaruhi perubahan penutupan lahan di Kabupaten Labura, yaitu jenis tanah (X1), kemiringan lereng (X2), curah hujan (X3), jumlah penduduk (X4), kepadatan penduduk (X5), jarak dari pusat kecamatan (X6), dan jarak dengan jalan utama (X7).

Setelah dilakukan Seleksi Bivariat dengan menggunakan metode LRA, diketahui bahwa ada enam dugaan variabel mempengaruhi perubahan tutupan lahan kecuali curah hujan. Setelah dilakukan analisis LRA pada perangkat lunak statistik maka muncul persamaan regresi seperti di bawah ini. Nilai positif pada variabel mengartikan bahwa semakin tinggi variabel tersebut, maka perubahan semakin sering terjadi, sebaliknya nilai negatif mengartikan bahwa semakin tinggi variabel, maka perubahan semakin jarang terjadi. Persamaan perubahan tutupan lahan hasil LRA adalah sebagai berikut.

$$
\begin{aligned}
& \mathrm{Y}=-0.068+0.81 \mathrm{X} 1+0.116 \mathrm{X} 2-0.00003 \mathrm{X} 4+0.408 \\
& \quad \mathrm{X} 5-0.00004 \mathrm{X} 6+0.18 \mathrm{X} 7
\end{aligned}
$$

\subsubsection{Faktor Jenis Tanah (X1)}

Variabel jenis tanah memberikan pengaruh positif pada perubahan tutupan lahan di Kabupaten Labura, dengan kata lain semakin baik dan subur jenis tanah, maka perubahan penutupan dan penggunaan lahan akan semakin terjadi. Perubahan tutupan lahan di Kabupaten Labura periode 2010-2019 dominan ke arah perkebunan sehingga semakin subur tanah maka semakin baik pertumbuhan tanaman. Kondisi ini cenderung memberikan akselerasi perubahan lahan hutan ke perkebunan yang dominan setiap tahunnya.

Tanah yang berstruktur baik akan membantu berfungsinya faktor-faktor pertumbuhan tanaman secara optimal, sedangkan tanah yang berstruktur jelek akan menyebabkan terhambatnya pertumbuhan tanaman Kualitas fisik tanah yang tidak bagus akan menyebabkan tanaman tumbuh tidak optimal karena perkembangan akar tanaman terganggu untuk mencari air dan unsur hara (Widodo and Kusuma, 2018). Perubahan hutan menjadi perkebunan kerap 114 terjadi pada beberapa daerah yang mengalami pemekaran wilayah (Heilmayr et al., 2016; Wibowo and Gintings, 2010) sehingga pada akhirnya terjadi fragmentasi lahan hutan ataupun perkebunan (Abdullah and Nakagoshi, 2007).

Sektor unggulan Kabupaten Labura adalah pertanian. Berdasarkan tutupan lahan, perkebunan yang terdiri dari kelapa sawit dan kelapa mendominasi wilayah kabupaten. Tidak hanya sebagai pemasok kebutuhan pangan, industiri kelapa sawit dan karet juga menjadi mata pencaharian warga masyarakat. Dengan banyaknya industri yang terus berkembang didorong oleh kondisi tanah yang baik sehingga luas perkebunan terus bertambah seiring waktu.

\subsubsection{Faktor Kemiringan Lereng (X2)}

Variabel kemiringan lereng memberikan pengaruh positif pada perubahan tutupan lahan di Kabupaten Labura, dengan kata lain semakin berbukit lerengnya, maka perubahan penutupan dan penggunaan lahan akan semakin terjadi. Salah satu faktor yang mempengaruhi perubahan penggunaan lahan adalah peningkatan pembukaan lahan perkebunan di lahan yang berbukit didukung oleh tanah yang optimal untuk pertumbuhan tanaman. Pembukaan perkebunan yang baru dapat meningkatkan perekonomian bagi individu individu baik masyarakat maupun pebisnis. Kawasan lahan yang berbukit dapat ditanami tanaman seperti pertanian sawah, perkebunan, dan hortkultura dengan pengaturan dan pengolahan yang benar. Hal ini dapat dilihat dari peta bahwa perubahan dominan terjadi pada daerah berbukit yang mempunyai lereng cenderung berbukit kecil. Penelitian dari berbagai wilayah menunjukan bahwa lahan yang relative data akan mengalami perubahan yang pesat (Valentin et al., 2008; Aroengbinang and Kaswanto, 2015; Luo et al., 2020).

\subsubsection{Faktor Jumlah Penduduk (X4)}

Notasi positif pada variabel jumlah penduduk memberikan pengaruh perubahan tutupan lahan, sehingga semakin banyak jumlah penduduk maka perubahan penutupan dan penggunaan lahan semakin jarang terjadi.

Seperti yang diketahui bahwa pertumbuhan penduduk yang semakin maju akan memberi dampak kepada peningkatan kebutuhan akan lahan. Adanya keterbatasan lahan, maka permasalahan penataan ruang semakin rumit, didukung oleh kondisi perekonomian masyarakat. Permasalahan tersebut menjadi sumber sengketa tanah yang terjadi secara umum, salah satunya tumpang tindih penggunaan tanah, terkait kebijakan pemerintah dalam pemanfaatan tanah seperti pemanfaatan dan penggunaan tanah yang tidak sesuai dengan Rencana Tata Ruang Wilayah (RTRW). Disamping itu kondisi tersebut perlu diwaspadai, terutama dengan pelaku bisnis dalam penggunaan dan pemanfaatan ruang yang semakin besar (Ernis, 2015). Hal ini terjadi di Kabupaten Labura yaitu banyak lahan diarahkan 
untuk dijual atau mengganti komoditas tanaman yang lebih menguntungkan sehingga membuat pembangunan kawasan kabupaten sampai saat ini tidak terlalu pesat.

\subsubsection{Faktor Kepadatan Penduduk (X5)}

Pada Kabupaten Labura, Kepadatan Penduduk memberikan fungsi positif terhadap perubahan tutupan dan penggunaan lahan yang ada sehingga semakin tinggi kepadatannya maka semakin meningkat perubahan yang terjadi terutama pada wilayah Kecamatan Kualuh Hulu. Berdasarkan hasil beberapa penelitian terdahulu dapat disimpulkan bahwa reaksi publik dan perubahan kebijakan perencanaan fisik akan menyebabkan peningkatan efisiensi pemanfaatan ruang atau lahan karena meningkatnya kepadatan penduduk di daerah yang lebih maju. Kualuh Hulu sebagai pusat pemerintahan kabupaten tentunya akan berkembang pesat dan dapat meningkatkan pembangunan kawasan di sekitarnya (Aroengbinang and Kaswanto, 2015; Shoshany and Goldshleger, 2002). Pembangunan kawasan dengan pertumbuhan penduduk di Indonesia yang pesat tentunya dapat diimbangi dengan konsep pembangunan Kawasan Perdesaan seperti yang diamanatkan oleh Undang-Undang No. 4 Tahun 2014 tentang Desa (Republik Indonesia, 2014).

\subsubsection{Faktor Jarak Pusat Kota (X6)}

Berdasarkan hasil analisis, ternyata variabel jarak pusat kota memberikan pengaruh signifikan terhadap perubahan penutupan lahan namun dalam hal yang berkebalikan. Variabel tersebut berpengaruh negatif di Kabupaten Labura. Semakin dekat lahan dari pusat kota maka semakin kecil perubahan tutupan lahan yang ada. Dilihat dari tutupan lahan Kabupaten Labura saat ini, pusat kota kabupaten belum mampu untuk menjadi 'magnet' bagi konversi yang memusat sehingga pembangunan masih tertarik ke arah luar menjauhi pusat pemerintahan kabupaten. Perkebunan dan pertanian yang lebih banyak mengalami perubahan berada jauh dari pusat pemukiman dan pemerintahan. Selain itu, karena karakteristik perekonomiannya yang agraris, pembangunan yang digagas oleh masyarakat secara swadaya di Kabupaten Labura terutama di bidang pertanian cenderung memilih lahan yang jauh dari pusat kecamatan karena kondisi lahannya yang masih baik dan harga lahannya yang relatif lebih murah dibandingkan di dekat kota.

\subsubsection{Faktor jarak dengan Jalan Utama (X7)}

Variabel jarak dengan jalan utama memberikan pengaruh positif pada perubahan tutupan lahan di Kabupaten Labura, dengan kata lain semakin jauh jarak dari jalan utama maka, maka perubahan penutupan dan penggunaan lahan akan semakin terjadi. Saat ini perubahan tutupan lahan pada Kabupaten Labura pesat terjadi pada perkebunan dan pertanian. Lanskap perkebunan dan pertanian yang teridentifikasi jauh dari jalan utama. Lahan yang ada sebagian besar merupakan perkebunan dan pertanian skala komersil sehingga sangat jarang kawasan akan berubah pesat. Hasil studi dan wawancara menunjukan bahwa perubahan ini disebabkan harga lahan yang murah, baik harga sewa maupun jual sehingga kecenderungan ini terjadi. Selain itu dengan adanya pembangunan infrastruktur pada wilayah perdesaaan juga memberikan kontribusi terhadap persepsi para petani dan pemilik modal bahwa jarak tidak memberikan dampak pada biaya (cost).

\subsection{Rekomendasi Kebijakan}

Perubahan tutupan lahan yang cenderung ke arah perkebunan disebabkan oleh Jenis Tanah (X1) sebesar 0.81 dan Kepadatan Penduduk (X5) sebesar 0.408. Sehingga rekomendasi yang diberikan terkait dengan kondisi tanah yang existing adalah zonasi tata ruang pada tingkat kecamatan dengan asumsi bahwa ada regulasi dalam mempertahankan kawasan konservasi agar tidak beralih menjadi lahan perkebunan kelapa sawit, karet, kelapa ataupun kopi (Montanarella and Panagos, 2021). Pesatnya pertumbuhan dan kepadatan penduduk tentunya perlu diimbangi dengan manajemen tata ruang untuk merencanakan pemenuhan kebutuhan akan ruang (space), untuk itu perlu dilakukan pengawasan terhadap kebutuhan ini seperti yang telah dilakukan di beberapa daerah (Assaf et al., 2021; Kaswanto and Nakagoshi, 2014).

\section{Kesimpulan}

Sebagai wilayah yang mengalami pemekaran pada tahun 2008, Kabupaten Labura mengalami perkembangan yang relatif lambat dalam kurun waktu kurang lebih 10 tahun, yakni 1,8 \% per tahun. Hal ini dibuktikan dari analisis yang menunjukan bahwa Kabupaten Labura mengalami perubahan tutupan lahan dari tahun 2010-2019 tetapi tutupan lahan dominan tetap (tidak berubah) setelah dianalisis. Namun, perkebunan mengalami peningkatan luasan lahan terbesar sedangkan hutan mangrove mengalami penurunan lahan terbesar kearah perkebunan. Sementara itu lahan terbangun mengalami penurunan luasan terkecil dengan perubahan dominan ke arah perkebunan. Hasil LRA menunjukan bahwa dari 7 variabel yang diuji, terdapat 6 variabel faktor pendorong perubahan tutupan lahan yang memiliki korelasi signifikan yaitu jenis tanah, kemiringan lereng, jumlah penduduk, kepadatan penduduk, jarak dari pusat kecamatan, dan jarak dengan jalan utama. Sementara 1 variabel yakni curah hujan tidak mempengaruhi perubahan tutupan lahan. Dilihat dari tutupan lahan kabupaten saat ini, pusat kota belum mampu untuk menjadi 'magnet' bagi pembangunan. Hal ini terjadi karena perkebunan dan pertanian yang lebih banyak mengalami perubahan berada jauh dari pusat pemukiman kota.

\section{Ucapan Terima Kasih}

Ucapan terima kasih disampaikan atas dukungan dari Kementerian Riset Teknologi dan Badan Riset Inovasi Nasional Republik Indonesia melalui skema Penelitian Terapan Unggulan Perguruan Tinggi (PTUPT) berjudul “"'Model 
Manajemen Lanskap Agroforestri sebagai Strategi Peningkatan Jasa Lanskap Mewujudkan Lanskap Rendah Karbon" dengan kontrak Nomor 2073/IT3.L1/PN/2021.

\section{DAFTAR PUSTAKA}

Abdullah, S.A., Nakagoshi, N. 2007. Forest Fragmentation and Its Correlation to Human Land Use Change in the State of Selangor, Peninsular Malaysia. For. Ecol. Manage.

Aroengbinang, B.W., Kaswanto. 2015. Driving Force Analysis of Landuse and Cover Changes in Cimandiri and Cibuni Watersheds. Procedia Environ. Sci.

Assaf, C., Adams, C., Ferreira, F.F., França, H. 2021. Land Use and Cover Modeling as a Tool for Analyzing Nature Conservation Policies - A Case Study of Juréia-Itatins. Land use policy Vol. 100. Pages 104895.

Bourne, L.S. 1982. Internal Structure of the City: Readings on Urban Form, Growth, and Policy. Oxford University Press, USA.

Ernis, Y. 2015. Penelitian Hukum Tentang Konsistensi Penggunaan Dan Pemanfaatan Tanah Sesuai Dengan Undang-Undang No. 26 Tahun 2007 Tentang Penataan Ruang. Pusat Penelitian dan Pengembangan Sistem Hukum Nasional Badan Pembinaan Hukum Nasional Kementerian Hukum dan Hak Asasi Manusia.

Fauzi, I.R., Bukit, E., Andriyanto, M., Istianto, I. 2016. Kelayakan Pengembangan Perkebunan Karet di Kabupaten Tanah Bumbu Kalimantan Selatan. J. Penelit. Karet.

Greenacre, M., Primicerio, R. 2013. Measures of Distance Between Samples: Euclidean, in: Multivariate Analysis of Ecological Data.

Heilmayr, R., Echeverría, C., Fuentes, R., Lambin, E.F., 2016. A Plantation-Dominated Forest Transition in Chile. Appl. Geogr.

Herman, Fahmuddin Agus, I. Las. 2009. Analisis Finansial dan Keuntungan yang Hilang dari Pengurangan Emisi Karbon Dioksida pada Perkebunan Kelapa Sawit. J. Penelit. dan Pengemb.

Jensen, J.R. 2005. Introductory Digital Image Processing: A Remote Sensing Perspective, Fourth Edition, Keith, C.C., Ed.; Prentice Hall Series in Geographic Information Science: Saddle River, NJ, USA.

Kaswanto, R.L., Nakagoshi, N. 2014. Landscape EcologyBased Approach for Assessing Pekarangan Condition to Preserve Protected Area in West Java.

Kim, T., 2017. A Basic Study on the Establishment of Evaluation Indicators and Improvement of Culture Streets: With a Focus on Jeju Island's Culture Streets. Arch. Des. Res.

Kurniati, A.C., Suharso, T.W., Surjono, S. 2012. Kajian Disparitas Sebagai Solusi dalam Penentuan Pemilihan Kecamatan Baru Kota Pasuruan. J. Tata Kota dan Drh. Vol. 2. Hal. 83-94.

Kurniawan, R., Pangestu, A.W. 2018. Analisis Pendapatan Petani Kelapa (Cocos nucifera L) di Desa Teluk Payo Kecamatan Banyuasin II Kabupaten Banyuasin. Soc. J. Ilmu-Ilmu Agribisnis.

Kustiawan, I. 1997. Konversi Lahan Pertanian di Pantai Utara Jawa. Prisma Vol. 1. Hal. 15-18.

Luo, Y., Lü, Y., Liu, L., Liang, H., Li, T., Ren, Y. 2020. Spatiotemporal Scale and Integrative Methods Matter for Quantifying the Driving Forces of Land Cover Change. Science of The Total Environment, Vol. 739. Pages 139622.
Montanarella, L., Panagos, P. 2021. The Relevance of Sustainable Soil Management within the European Green Deal. Land use policy Vol. 100. Pages 104950.

Pickles, J. 1995. Ground Truth: the Social Implications of Geographic Information Systems. Gr. truth Soc. Implic. Geogr. Inf. Syst.

Republik Indonesia. 2014. Undang-Undang Nomor 6 Tahun 2014 tentang Desa, Jakarta: Biro Hukum Organisasi dan Tata Laksana.

Republik Indonesia. 2008. UU Nomor 23 Tahun 2008 Tentang Pembentukan Kabupaten Labuhanbatu Utara di Provinsi Sumatera Utara.

Republik Indonesia. 2004. Undang-undang Nomor 32 tahun 2004 tentang Pemerintahan Daerah.

Rujoiu-Mare, M.-R., Mihai, B.-A. 2016. Mapping Land Cover Using Remote Sensing Data and GIS Techniques: A Case Study of Prahova Subcarpathians. Procedia Environ. Sci.

Shoshany, M., Goldshleger, N. 2002. Land-Use and Population Density Changes in Israel-1950 to 1990: Analysis of Regional and Local Trends. Land Use Policy.

Standar Nasional Indonesia. 2010. Klasifikasi Penutup Lahan, Jakarta. Indonesia.

Stehman, S. V. 1997. Selecting and Interpreting Measures of Thematic Classification Accuracy. Remote Sens. Environ.Vol. 62. Pages 77-89.

Sunarno, H.S., 2006. Hukum Pemerintahan Daerah di Indonesia. Sinar Grafika, Jakarta.

Valentin, C., Agus, F., Alamban, R., Boosaner, A., Bricquet, J. P., Chaplot, V., de Guzman, T., de Rouw, A., Janeau, J. L., Orange, D., Phachomphonh, K., Do Duy Phai, Podwojewski, P., Ribolzi, O., Silvera, N., Subagyono, K., Thiébaux, J. P., Tran Duc Toan, Vadari, T. 2008. Runoff and Sediment Losses from 27 Upland Catchments in Southeast Asia: Impact of Rapid Land Use Changes and Conservation Practices. Agriculture, Ecosystems \& Environment, Vol. 128 No. 4. Pages 225-238.

Wibowo, A., Gintings, A.N. 2010. Degradasi dan Upaya Pelestarian Hutan. Membalik Kecenderungan Degrad. Sumber Daya Lahan dan Air.

Widodo, K.., Kusuma, Z. 2018. Pengaruh Kompos terhadap Sifat Fisik Tanah dan Pertumbuhan Tanaman Jagung di Inceptisol. Tanah dan Sumberd. Lahan Vol. 5. Hal. 13-14.

Wiggers, M.J., Nuarsa, I.W., Putra, I.D.N.N. 2020. Analisis Perubahan Penggunaan Lahan Pesisir di Kecamatan Batu Layar, Kabupaten Lombok Barat Pada Tahun 2002 dan 2019. J. Mar. Res. Technol. Vol. 3. Hal. 68-74.

Wulansari, H., 2018. Uji Akurasi Klasifikasi Penggunaan Lahan dengan Menggunakan Metode Defuzzifikasi Maximum Likelihood Berbasis Citra Alos Avnir-2. BHUMI J. Agrar. dan Pertanahan; Vol. 3 No. 1.

Zhou, Q., 2017. Digital Elevation Model and Digital Surface Model, in: International Encyclopedia of Geography: People, the Earth, Environment and Technology. 